\title{
Is there a long-lasting effect of pelvic floor muscle training in women with urinary incontinence after ischemic stroke?
}

\author{
S. Tibaek • G. Gard • R. Jensen
}

Published online: 15 November 2007

(C) International Urogynecology Journal 2007

The manuscript supplied to the publisher omitted to mention that the author Sigrid Tibaek is also affiliated to the Division of Physiotherapy at Lund University, Sweden. The complete affiliations are reproduced here.

"Physiotherapi" in this affiliation should read "Physiotherapy".

The online version of the original article can be found at http://dx.doi. org/10.1007/s00192-006-0137-3.

\footnotetext{
S. Tibaek $(\bowtie)$

Department of Geriatrics and Rheumatology,

Copenhagen University Hospital,

Glostrup, Nordre Ringvej,

Glostrup 2600, Denmark

e-mail: Sigrid.Tibaek@get2net.dk

S. Tibaek $\cdot$ G. Gard $(\bowtie)$

Department of Health Sciences, Division of Physiotherapy,

Lund University,

Lund, Sweden

e-mail: Gunvor.Gard@med.lu.se

R. Jensen $(\bowtie)$

Department of Neurology, Copenhagen University Hospital,

Glostrup, Nordre Ringvej,

Glostrup 2600, Denmark

e-mail: rj@dadlnet.dk
} 